\title{
The Optimization of Irrigation Networks Using Genetic Algorithms
}

\author{
Francisco Fernando Noronha Marcuzzo', Edson Cezar Wendland 2 \\ ${ }^{1}$ Department of Hydrology Applied, Geological Survey of Brazil, Porto Alegre, Brazil \\ ${ }^{2}$ Department of Hydraulic, School of Engineering of São Carlos, University of São Paulo, São Carlos, Brazil \\ Email: francisco.marcuzzo@cprm.gov.br, ew@sc.usp.br
}

Received 5 June 2014; revised 2 July 2014; accepted 28 July 2014

Copyright (C) 2014 by authors and Scientific Research Publishing Inc.

This work is licensed under the Creative Commons Attribution International License (CC BY).

http://creativecommons.org/licenses/by/4.0/

(c) (i) Open Access

\begin{abstract}
Mathematical-computational optimisation models of irrigation networks with a distributed flow that are capable of providing hydraulic data are important for understanding the behaviour of a system in relation to the distribution of the hydraulic head (energy) and the pressure in the pipes of the network. The objective of this study was to examine the distribution of the parameters of hydraulic irrigation pipes, which were optimised using genetic algorithms. The degree of the optimisation was evaluated with the help of the genetic algorithms based on the diameters of stretch of the network: two for the lateral lines, four for the derivation lines, four for the secondary lines and one for the main line. A MatLab code was developed that considered all of the losses of energy, both distributed losses and those at specific locations between the beginning of the network and the pump system. The sensitivity analysis was based on the variations in the slope of the ground $(0 \%, 2.5 \%$ and $5 \%)$. The results show that for pipes with a distributed flow, the influence of the behaviour of the kinetic energy in the pipe contributed to the distance between the energy lines and the piezometric lines at the beginning of each stretch after the decrease in the diameter of the pipes. At the end of the pipes, the values of the energy lines and the piezometric lines were very similar, and they were essentially the same for the final emitter.
\end{abstract}

\section{Keywords}

Conduits under Pressure, Hydraulic Head, Micro-Sprinkler Irrigation, Mathematical Optimisation

\section{Introduction}

Localised irrigation is the application of small amounts of water, normally the volume that the plant will use for a few days, with an application frequency greater than in conventional irrigation. These systems normally use 
small amounts of energy for pumping, pressure and flow. However, localised irrigation networks may display significant variations in the drippers, which leads to a lack of uniformity of their implementation in the field.

In a study of the hydraulic performance of the lateral lines of drip tubes, [1] has stated that localised irrigation allows for the best possible control over the irrigation water applied because it operates with reduced flows and higher irrigation frequencies. In their field research on the hydraulic parameters of micro-sprinkler systems, [2] has observed the solid functioning of the system, with high coefficients of uniformity, good efficiency of application and little variation in the flow and pressure of the system, indicating excellent quality of the implementation of the irrigation system. [3] has observed that the hydraulic performance of a low-pressure irrigation system that was designed and fit dimensionally using a computer program and installed in the field was considered satisfactory because it exhibited good efficiency and excellent hydraulic uniformity.

In a study of the optimisation of the network with different slopes, [4] has reported that the use of two diameters in the derivation line improved the uniformity of the flow of the derivation line. In addition, [5] [6] have performed optimisation studies and analyses on the dimensions of the irrigation networks by considering the different options for the operation of the system as the basis for the decision-making process. These studies showed excellent results for mathematical optimisation, which is an important decision-making tool in the compromise between the best system management and the required dimensions of the distribution network.

In a study using different indices to define the standard water use in irrigation systems, farmers cultivating onions using a system with micro-sprinklers have increased their production, while using less water [7]. In addition, a study comparing two irrigation methods (dripping and sprinklers) for sunflower seeds plants in the Mediterranean has shown that the water volume is important for increased productivity and the yield of sunflower oil [8].

The local head loss, which occurs when the flow is disrupted by an obstruction in the tube, is a relevant criterion in the evaluation of lateral drip lines, especially when self-compensating drippers are used [9]. The high uniformity of the distribution of water allows for the optimisation of the use of water, energy and nutrients; to guarantee this, appropriate hydraulic design is indispensible, requiring that the hydraulic characteristics of the components are known [10].

Considering the optimisation objectives for the rehabilitation of a water supply network, the use of a standard genetic algorithm improves both the convergence speed and the rationality and viability of the solutions for the problems of mathematical programming [11].

[12] has conducted a study of the irrigation management in the Ceyhan River Basin in Turkey using dynamic programming with successive approximations (DPSA). Given that the benefit may be defined as an ideal value when considering the balance between irrigation water and energy production, it was observed in the above study that when the irrigation demand was increased, the production of energy and the benefits of producing energy decreased.

In a dam project based on the simulation of optimisation through a genetic algorithm, [13] has demonstrated a significant cost reduction using a Non-linear Optimisation Formulation (NLOF).

This article presents a hydraulic study of a water distribution network for localised irrigation that was obtained through optimised simulation using genetic algorithms, including the consideration of the variation in the slope of the ground. Thus, we performed a numeric simulation with the optimised variables to analyse the behaviour of the hydraulic design elements throughout the pipes where there were derivations of the flow distributed in the tubing.

\section{Material and Methods}

The distribution network for localised irrigation was installed in an area that included 68.4 useful hectares. Figure 1 presents the distribution and the dimensions of the hydraulic network.

The hydraulic network of the localised irrigation system studied in this work consisted of emitters (micro-sprinkles or drippers), lateral lines (in which the emitters were located), derivation lines (which distributed water to the lateral lines), secondary lines (which distributed water to the derivation lines), the main line or the adductor line (which distributed water to the secondary lines), suction tubing, valves, registers, filters (sand and disc) and the control panel.

Table 1 presents in detail the different stretches of piping used in this study, their lengths, whether the ground was even or upward or downward sloping (based on the direction of the flow of water), the material used in the 


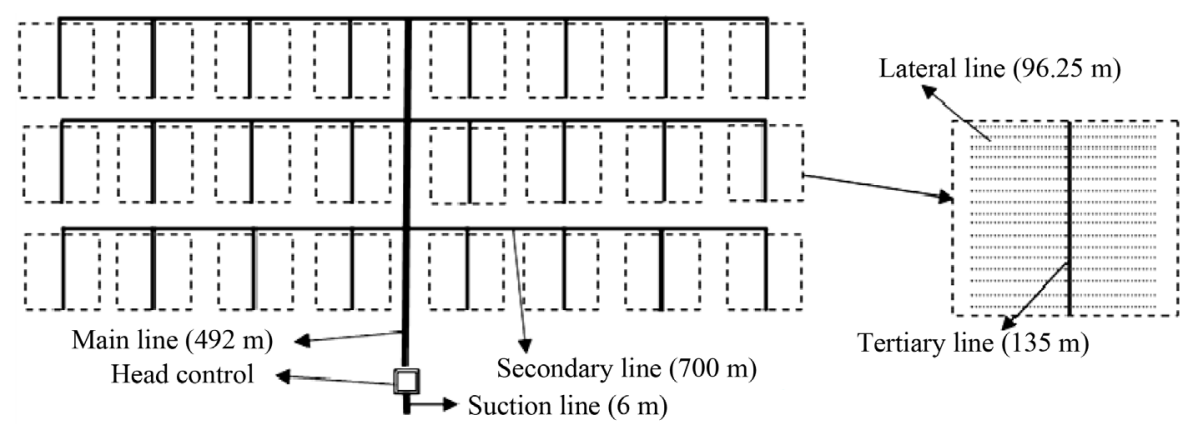

Figure 1. The design of the micro-sprinkler network with the respective lengths of pipe used.

Table 1. Details of the adopted irrigation network.

\begin{tabular}{ccccc}
\hline Stretch of the Network & Position of the Tubing & Material & Length & Internal Diameter mm \\
\hline Lateral Line & Level & Polyethylene & 96.25 & $21.7 ; 17.8$ \\
Derivation Line & Decline & PVC & 135 & $120.0 ; 97.6 ; 72.5 ; 48.1$ \\
Secondary Line & Level & PVC & 700 & $204.2 ; 144.0 ; 120.0 ; 97.6$ \\
Main Line & Incline & PVC & 492 & 204.2 \\
Suction Line & Incline or Level & PVC & 6 & 262.0 \\
\hline
\end{tabular}

production of these elements and the internal diameters used in each stretch of optimised tubing. The slopes of the ground were $0 \%, 2.5 \%$ and $5 \%$.

To calculate the adjustment factor for the decrease in the loss of pressure due to friction of the tubing, the following adjustment equation proposed by [14] was used:

$$
F L i=\frac{N T D i \times\left(\left(\frac{1}{m+1}\right)+\left(\frac{1}{2 N T D i}\right)+\left(\frac{(m-1)^{0.5}}{6 N T D i^{2}}\right)\right)+x L i-1}{N T D i+x L i-1}
$$

in which:

$F L i$ is the adjustment factor for a decrease in the loss of pressure due to friction of the tubing $i$;

$N T D i$ is the total number of derivations for the tubing $i$;

$m$ is the exponent for the equation of unitary head loss; and

$x \mathrm{Li}$ is the ratio of the distance from the beginning of line $i$ to the first derivation, in relation to the distance between the other derivations.

To calculate the coefficient of friction, the following general equation proposed by [15] was used, which is used for rolling, smooth turbulent, transition and rigorous turbulent flows:

$$
\text { fin }=\left\{\left(\frac{64}{\text { Rein }}\right)^{8}+9.5\left[\ln \left(\frac{\varepsilon}{3,7 \text { Din }}+\frac{5.74}{\text { Rein }^{0,9}}\right)-\left(\frac{2500}{\text { Rein }}\right)^{6}\right]^{-16}\right\}^{0,125}
$$

in which:

fin is the coefficient of friction for the calculation of the head loss in the tubing in line $i$ in stretch $n$ (dimensionless);

Rein is the Reynolds number in line $i$ in stretch $n$ (dimensionless);

$\varepsilon$ is the absolute roughness of the tubing used in line $i(\mathrm{~mm})$; and

Din is the diameter of the pipes in line $i$ in stretch $n$ (m).

The unit head loss was determined using the Darcy-Weisbach equation [16], as follows:

$$
\operatorname{Jin}=\frac{\text { fin }}{\operatorname{Din}} \frac{\operatorname{Vin}^{2}}{2 g}
$$


in which:

Jin is the unit head loss in line $i$ in stretch $n\left(\mathrm{~m} \cdot \mathrm{m}^{-1}\right)$;

fin is the coefficient of friction in line $i$ in stretch $n$ (dimensionless);

Din is the diameter of the pipes in line $i$ in stretch $n(\mathrm{~m})$;

Vin is the velocity of the water in line $i$ in stretch $n\left(\mathrm{~m} \cdot \mathrm{s}^{-1}\right)$; and

$g$ is the acceleration of gravity $\left(\mathrm{m}\left[\mathrm{s}^{2}\right]^{1}\right)$.

The sum of the unit head loss with a distributed slope of the ground was calculated using the following:

$$
\text { fin }=(\text { Jin FLi LLin })+P C L i n+D Z L L i n
$$

in which:

$h$ fin is the sum of the head loss and the slope of the ground in line $i$ in stretch $n$ (mca);

Jin is the unit head loss in line $i$ in stretch $n\left(\mathrm{~m} \cdot \mathrm{m}^{-1}\right)$;

$F L i$ is the adjustment factor for the decrease in the pressure loss due to friction in the tubing $i$;

LLin is the length of line $i$ in stretch $n(\mathrm{~m})$;

PCLin is the local head loss from the emitters in the tubing in line $i$ in stretch $n$ (m); and

DZLLin is the incline or decline distributed by the loss of water in line $i$ in stretch $n(\mathrm{~m})$.

The optimisation process of the dimensions began with the lateral line, in which the emitters were located. The flow was determined for each emitter according to the water needs of the plants that would be irrigated. The sum of the flow of all of the emitters indicated the flow that should be available at the beginning of the lateral line. The calculation of the dimensions was performed stretch by stretch, from the beginning of the line until the end, subtracting the distributed flow from the previous stretch. This principle was adopted for the lateral lines, the derivation lines and the secondary lines. For the main line (adductor) and the suction line, the calculation of the dimensions was not performed stretch by stretch because there were no derivations that simultaneously received water.

Because the dimensioning should be performed stretch-by-stretch in a network with a distributed flow, premeasurement of the tubes in the network was necessary.

The determination of the flows in the tubes of the network is fundamentally important in the design of the code for the capability function, whether it be the entire flow at the beginning of the piping or the fractioned flow for each derivation (emitters and piping).

The methodology that was used for the economic analysis implemented by the computational code is described below. In the calculation of the total cost, the fixed cost of installation and the variable operational costs were both considered.

Using annual interest, the capital recovery factor (CRF) provided a coefficient that allowed for the calculation of the fixed annual cost of an investment based on the value of the investment. This calculation took into account the useful life of the equipment and the per annum interest rate using the following equation:

$$
C R F=\frac{J(J+1)^{V}}{(J+1)^{V}-1}
$$

in which:

$C R F$ is the capital recovery factor (decimal);

$J$ is the annual interest rate (decimal); and

$V$ is the useful life of the equipment (years).

The calculation of the fixed annual cost took into account the CRF and the price of acquiring the system, using the following equation:

$$
C F=F R C \times C E Q
$$

in which:

$C F$ is the fixed annual cost $\left(\mathrm{R} \$ \mathrm{year}^{-1} \cdot \mathrm{ha}^{-1}\right)$;

$F R C$ is the capital recovery factor (decimal); and

$C E Q$ is the price of acquiring the irrigation system $\left(\mathrm{R} \$ \cdot \mathrm{ha}^{-1}\right)$.

The costs of both energy and water were included in the calculation of the annual variable costs of irrigation.

For the cost of energy, it is important to consider the method of charging for electricity. According to a reso- 
lution by the National Agency of Electrical Energy DOU no. 313 from 06/04/2006 [17], this irrigation project fell under Group B-the rural sector category-with a payment for consumption of only $0.1768 \mathrm{R} \$ \cdot \mathrm{kW}^{-1}$.

The electricity provider for the state of Sao Paulo (Power Company of São Paulo), designates a discount of $60 \%$ on the tariff for the rural sector between the hours of 21:30 and 06:00 (a "window" of use of 8.5 hours), which would result in a rate of $0.0707 \mathrm{R} \$ \mathrm{~kW}^{-1}$ for this time frame. Through heuristics, the system could be adjusted to function for 4.25 hours in two cycles per day, reducing the flow through the project and generating savings in the piping and power required; another option would be to use a cycle of 8.5 hours, depending on the preferred objective. This adjustment could be completed by increasing the flow of the emitters according to the flow curve versus the pressure provided by the manufacturer or by simply selecting another emitter. The choice of adjustment would depend on how many days the irrigation would last and how many sectors would be irrigated per day, with the operational units based on the system that would be installed.

The fee for the use of water was calculated based on the evapotranspiration of the crop, the number of irrigation days per month of operation of the system per year and the price of water $\left(\mathrm{R} \$ \cdot \mathrm{m}^{-3}\right)$. To make the model broader and more realistic, a water cost of $0.01 \mathrm{R} \$ \cdot \mathrm{m}^{-3}$ was adopted as an entrance parameter for the operation cost.

The total cost (the capability function to be optimised) was the sum of the fixed annual costs (installation of the irrigation system) and the variable annual costs (operational costs), calculated using the following equation:

$$
f=\frac{(C E Q \cdot F R C)+C T E+C A G T}{A U I}
$$

in which:

$f$ is the total cost of the irrigation network $\left(\mathrm{R} \$ \cdot \mathrm{year}^{-1} \cdot \mathrm{ha}^{-1}\right)$;

CTE is the total cost of electricity $\left(\mathrm{R} \$ \cdot\right.$ year $\left.^{-1}\right)$;

CATG is the total cost of water $\left(\mathrm{R} \$ \cdot\right.$ year $\left.^{-1}\right)$; and

$A U I$ is the useful irrigated area (ha).

The code for the optimised design was developed using MatLab. For the optimisation, the genetic operators were used from the MatLab toolbox.

The sensitivity analysis evaluated the effects of the operational unit of the system over the hydraulics (energy and pressure), based on the variation in the slope of the terrain. Sensitivity analysis is the measurement of the magnitude of the alteration of the final result caused by a predetermined change of one or more factors of the project, which means that the projected model is tested to determine the most relevant elements for the design decision. Thus, with various design parameters, it would be possible to select those parameters that are most sensitive, that is, those that have the most the influence over the analysis [18] [19].

The complete algorithm for the optimized design is in [20] and each analysis step for better presentations is in [21] [22]. The sensitivity analysis can be finding in [23].

\section{Results and Discussion}

\section{The Hydraulic Analysis of the Lateral Line}

Figure 2 presents the variation in the velocity and the distributed flow in the lateral line in relation to the internal diameter of the piping.

In Figure 2, the direct influence of the diameter of the tubing is apparent, with a distributed flow and with an increase in the velocity of the flow when the diameter of the first stretch of tubing experienced a contraction down to the diameter of the second stretch of tubing. This increase in the flow velocity occurred when there was a swift decrease in the internal area of the tubing and the flow in the closest emitters was insufficient to decrease the velocity around the point of contraction. After the 13th emitter, 5 emitters were necessary (after the 19th emitter), such that that velocity of the flow was once again less than that of the 13th emitter in the lateral line.

Figure 3 shows the Reynolds number for the emitters and the regions that represent turbulent, transitional and rolling flows, as determined according to Harpa de Nikuradse [16].

The descriptive analysis in Figure 3 shows that the flow of the lateral line began and remained turbulent in the tubing, with 25 emitters in this part of the flow, until passing through a short stretch of flow in transition and then ending in a rolling flow. With this outflow and with a distributed flow, the velocity and the diameter of the tubing (as calculated in Figure 2) had a direct result on the variation in the Reynolds number and the type of 


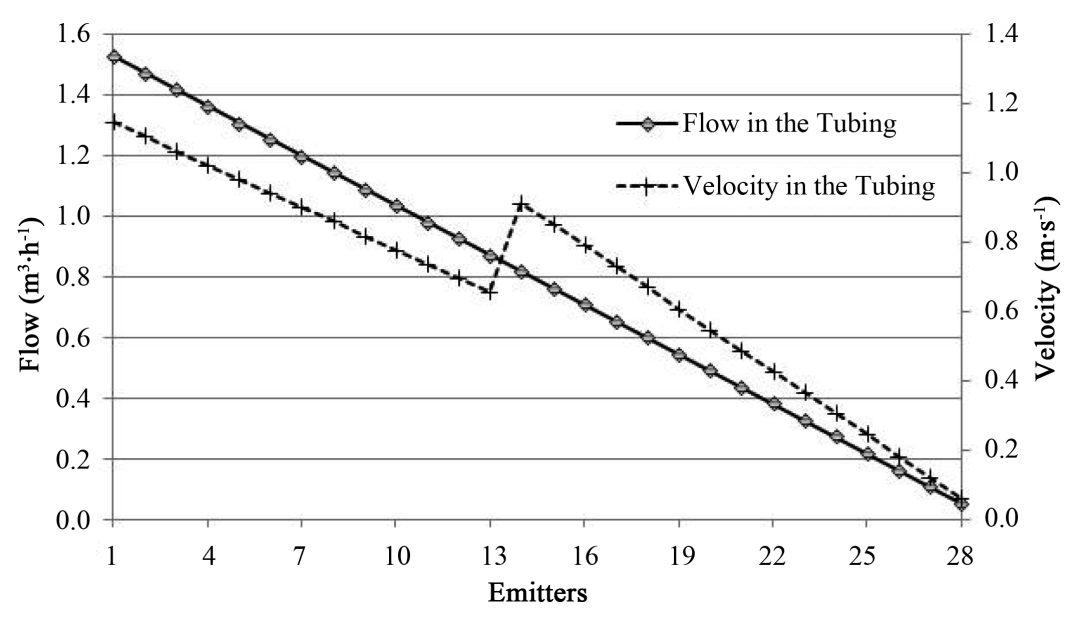

Figure 2. The distributed flow and velocity calculated in the design of the lateral line, with two different internal diameters in the tubing.

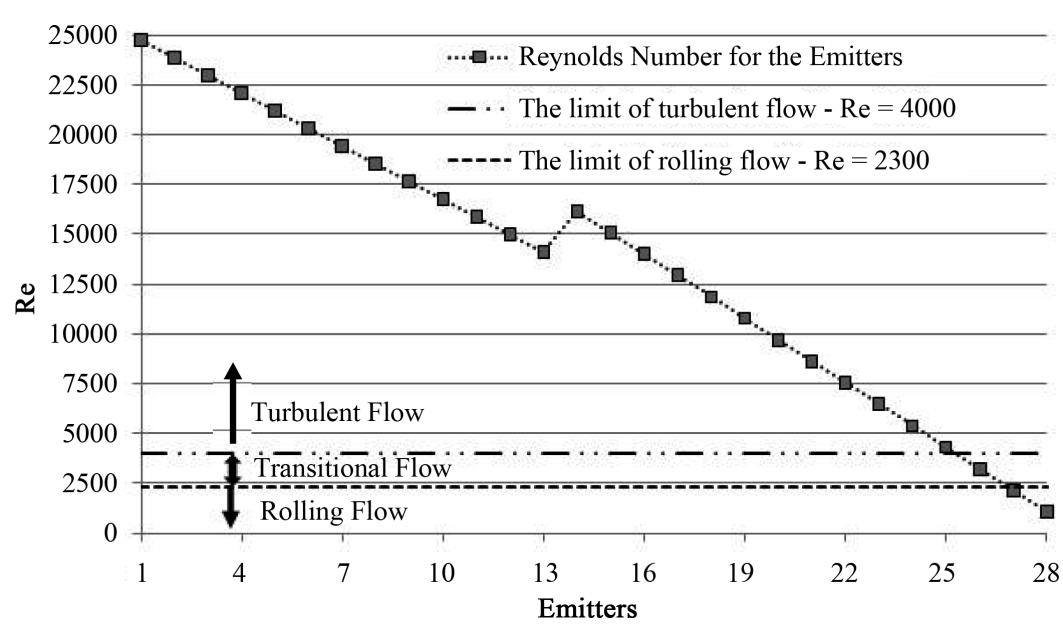

Figure 3. The Reynolds number for the emitters and the regions that represent rigorous, transitional and rolling flows.

flow in the lateral line. This effect on the type of flow demonstrated that the selection of the equation to calculate the friction factor was particularly important for smooth tubes, such as those made of polyethylene or PVC (often used in the design of irrigation networks), because the type of flow may change, as in Figure 3, in which the polyethylene tubing was under a distributed flow.

Figure 4 presents the local head loss in the contraction of the tubing and the variation in the local head loss throughout the emitters and the head loss unit between the emitters, the friction factor and the kinetic energy that all resulted from the scaling of the lateral line with a distributed flow. With a distributed flow, the variation in these scaling parameters corresponded to the tendency determined by the internal diameter of the tubing and the velocity of the outflow (Figure 2).

The local head loss with the contraction of the tubing was small $(0.0045 \mathrm{mca})$ in comparison with the head loss unit (0.0650) and the head loss between the emitters attached to the lateral line $(0.0212 \mathrm{mca})$ at the point of contraction of the tubing. The variation in the friction factor (from 0.0246 mca in the first emitter up to 0.0594 mca in the last emitter) throughout the lateral line tended to be inversely proportional to the variation in the Reynolds number presented in Figure 3. However, it can be seen that at emitter point 26, there was a slight tendency for a decrease in the friction factor and that at emitter point 27, there was an exacerbated decrease followed by a swift and accentuated increase at the final emitter point. This phenomenon occurred because of the intrinsic characteristics of the calculation of the friction factor and its variations and may be observed by analysing the polyethylene tubing (0.0015) in the Moody diagram. 


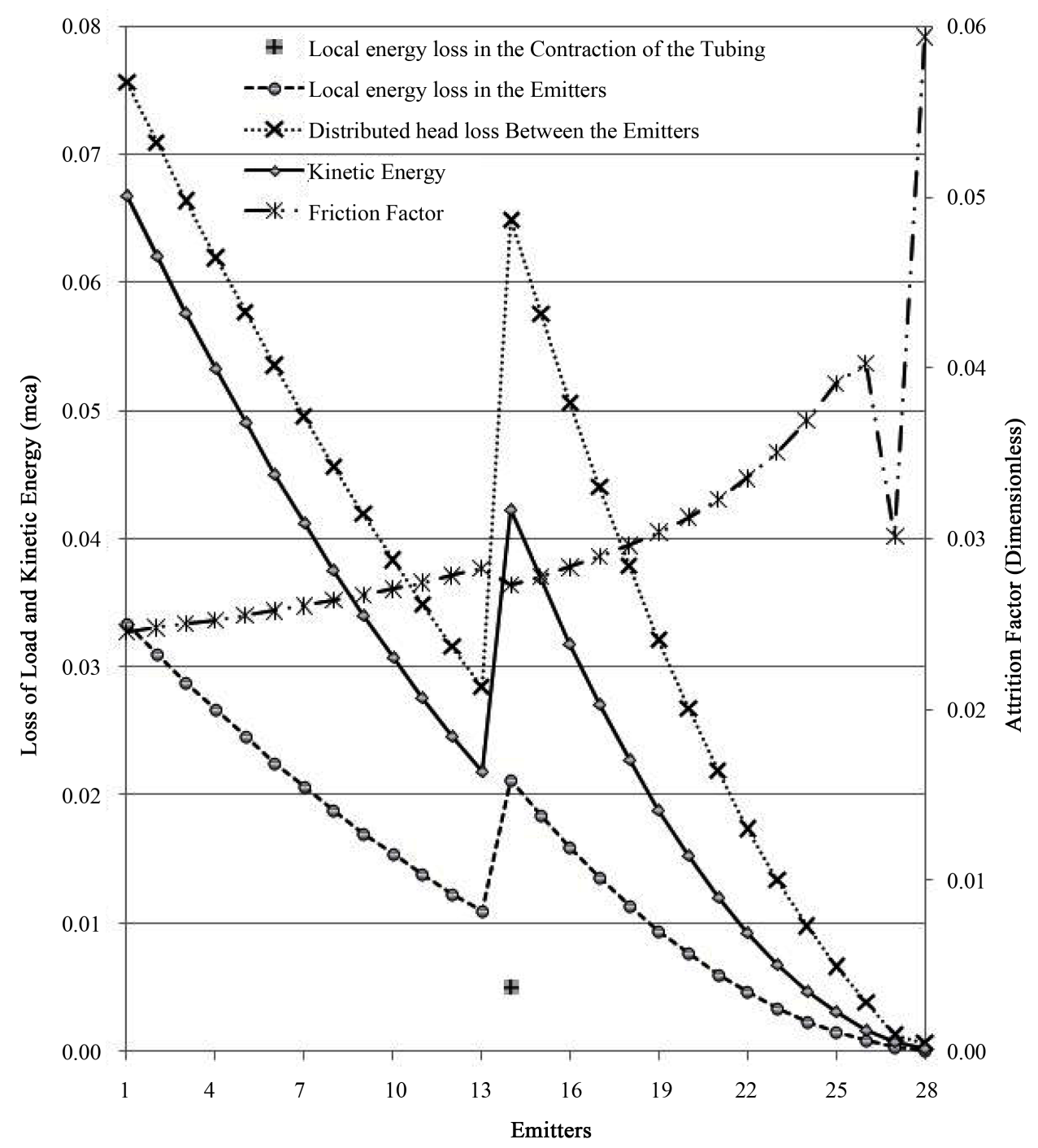

Figure 4. The local head loss in the contraction of the tubing and the variation in the local head loss throughout the emitters and the head loss unit between the emitters, the friction factor and the kinetic energy in the lateral line under a distributed flow. The data were obtained from the design of the network.

The influence of the kinetic energy (Figure 4) in the tubing contributed to the distance between the energy lines and the piezometric line at the beginning of the first and second stretches of the tubing. At the end of the tubing, after the 26th emitter, the values remained very similar, and they were essentially equal for the final emitter (28), where the kinetic energy was very close to zero.

The small amount of variation (9.1\%) between the highest (16.66 mca) and the lowest value of the piezometric head (15.14 mca) at the emission points in the lateral line caused a greater uniformity of emission in the operational unit.

The variation in the flow throughout the lateral line tended to stabilise concomitant with the stabilisation of the piezometric line, whereas the flow in each emitter was determined as a function of the pressure head at the emission point. More details on the influence of the variation of the piezometric line in the floss of the emitters will be presented in the hydraulic analysis of the entire operational unit (lateral lines attached to a derivation line) with the different slopes in the terrain.

Figure 5 presents the relationship between the energy lines and the piezometric lines obtained from the network plan and the flow in the emitters, with the piezometric head in each emitter. 


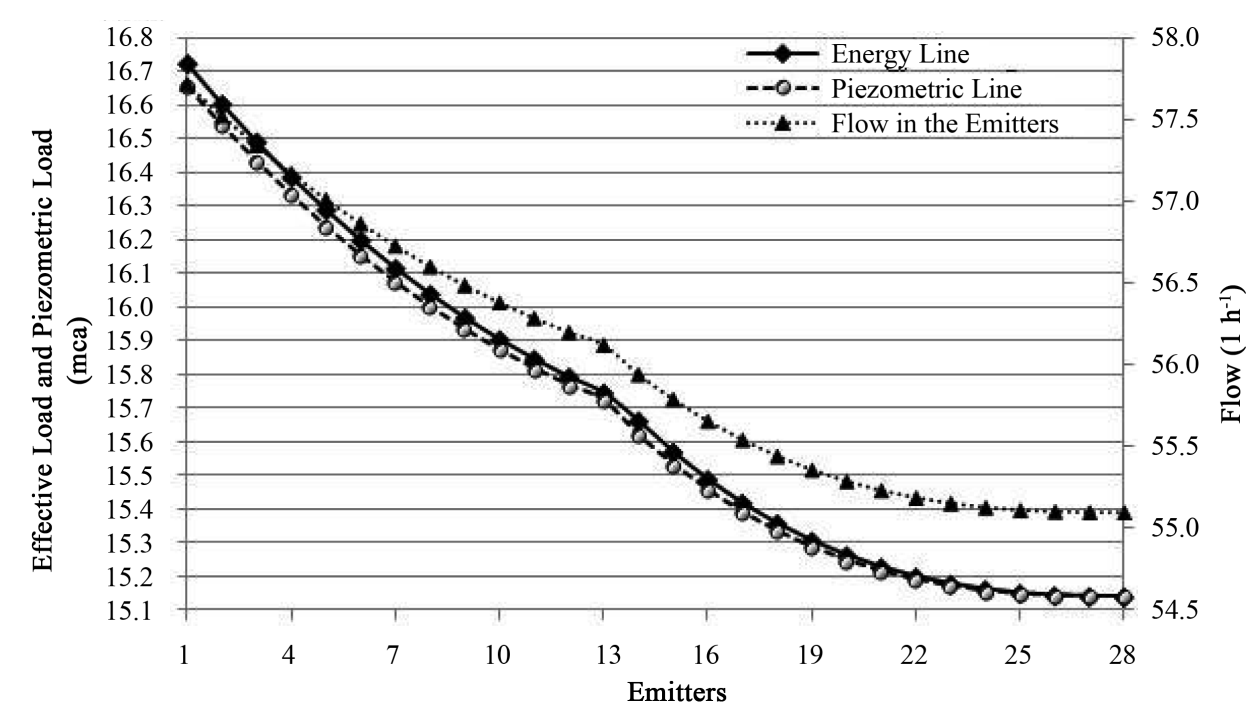

Figure 5. The variation between the energy lines and piezometric lines obtained from the dimensions of the network and the flow in the emitters, with the piezometric head in each emitter.

Figures 6-8 present the variation in the velocity of the outflow in the derivation line in comparison with the flow and the internal diameter of the tubing for the slopes of $0 \%, 2.5 \%$ and $5 \%$, respectively, calculated using the dimensions of the irrigation network.

The velocity increased at the outflow, even when the tubing had a distributed flow, and thus, there was a tendency toward a decrease in the velocity at the outflow, which led to an accentuated decrease in the internal area of the tubing.

In Figures 6-8, a lower average velocity $\left(1.49 \mathrm{~m} \cdot \mathrm{s}^{-1}\right)$ is observed in the tubing for a $0 \%$ slope in the terrain compared with the tubing for the $2.5 \%\left(1.71 \mathrm{~m} \cdot \mathrm{s}^{-1}\right)$ and $5 \%\left(1.80 \mathrm{~m} \cdot \mathrm{s}^{-1}\right)$ slopes. Thus, there tended to be an increase in the average velocity in the tubing of the derivation line when there was an increase in the slope with the same distributed flow.

A greater magnitude change $\left(1.59 \mathrm{~m} \cdot \mathrm{s}^{-1}\right)$ was also noted between the minimum velocity $\left(0.47 \mathrm{~m} \cdot \mathrm{s}^{-1}\right)$ and the maximum velocity $\left(2.05 \mathrm{~m} \cdot \mathrm{s}^{-1}\right)$ for a slope of $0 \%$, as compared with the magnitude change for a slope of $2.5 \%$ $\left(2.00 \mathrm{~m} \cdot \mathrm{s}^{-1}\right.$, with a maximum of $2.46 \cdot \mathrm{m} \mathrm{s}^{-1}$ and a minimum of $\left.0.47 \mathrm{~m} \cdot \mathrm{s}^{-1}\right)$ and $5 \%\left(2.02 \mathrm{~m} \cdot \mathrm{s}^{-1}\right.$, with a maximum of $2.49 \mathrm{~m} \cdot \mathrm{s}^{-1}$ and a minimum of $0.47 \mathrm{~m} \cdot \mathrm{s}^{-1}$ ).

Figures 9-11 present the variation in the Reynolds number along the derivation line for the slopes of $0 \%, 2.5 \%$ and $5 \%$, respectively. The variation in the Reynolds number along the derivation line followed the tendency represented in Figures 6-8. With the contraction of the diameters, there was an increase in the outflow velocity, causing a local increase in the Reynolds number, which was directly reflected in the other hydraulic design parameters.

The smallest variation in the Reynolds number was obtained with a $0 \%$ slope in the terrain, with a value of $89.2 \%$, followed by a slope of $2.5 \%$, with $90.3 \%$ variation and, lastly, a slope of $5 \%$, with a variation of $90.7 \%$.

Figures 12-14 present the data obtained from the dimensioning of the irrigation network, with a local head loss with 3 contractions in the tubing, including the local head loss behaviour with the attachment of the lateral lines, the head loss unit between the lateral lines and the friction factor and kinetic energy of the derivation line under a distributed flow. The internal area of the tubing and the velocity of the outflow under a distributed flow determined the behaviour of these parameters in the dimensions of the tubing (Figures 6-8). The local head loss in the contraction of the tubing was the smallest at the first contraction $(0.0247,0.0395$ and 0.0447 mca for $0 \%$, $2.5 \%$ and $5 \%$ slopes, respectively) in comparison with the rest of the contractions. The local head loss estimates for the second contraction (0.0464, 0.0664 and 0.0628 mca for $0 \%, 2.5 \%$ and $5 \%$ slopes, respectively) were, in general, lower than those for the third contraction ( $0.0668,0.0576$ and 0.0873 mca for $0 \%, 2.5 \%$ and $5 \%$ slopes, respectively), with the exception of the third contraction of the tubing for the $2.5 \%$ slope, which displayed a lower value that that of the $5 \%$ slope.

As shown in Figures 12-14, there was less variation in all of the parameters studied for a slope of $0 \%$, with a 


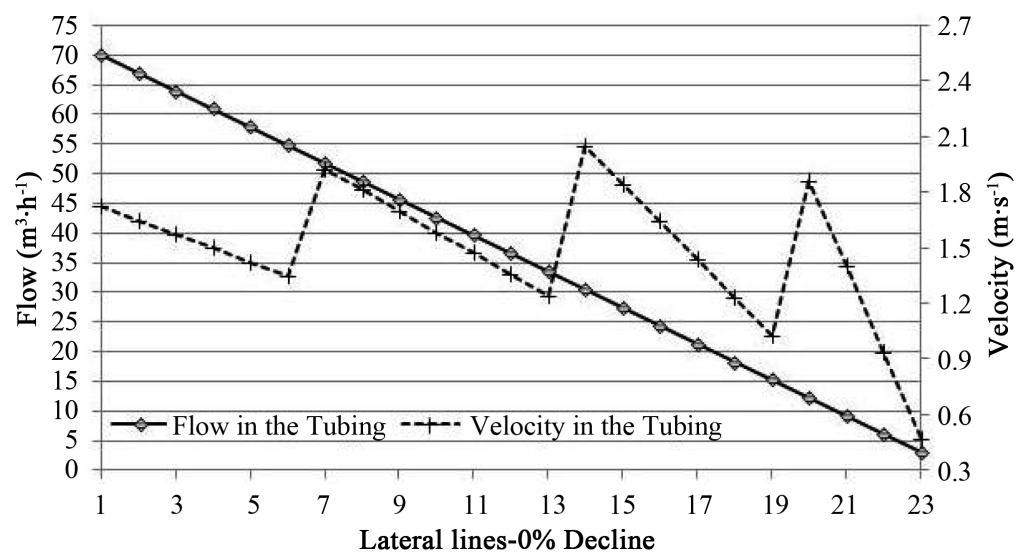

Figure 6. The variation in the calculated velocity in the dimensions of the derivation line, with a distributed flow in the tubing and different diameters in each stretch of the tubing $(\mathrm{DLD} 1=120.0 \mathrm{~mm}, \mathrm{DLD} 2=97.6 \mathrm{~mm}$, DLD3 $=72.5$ $\mathrm{mm}$ and DLD4 $=48.1 \mathrm{~mm}$ ) for a slope of $0 \%$.

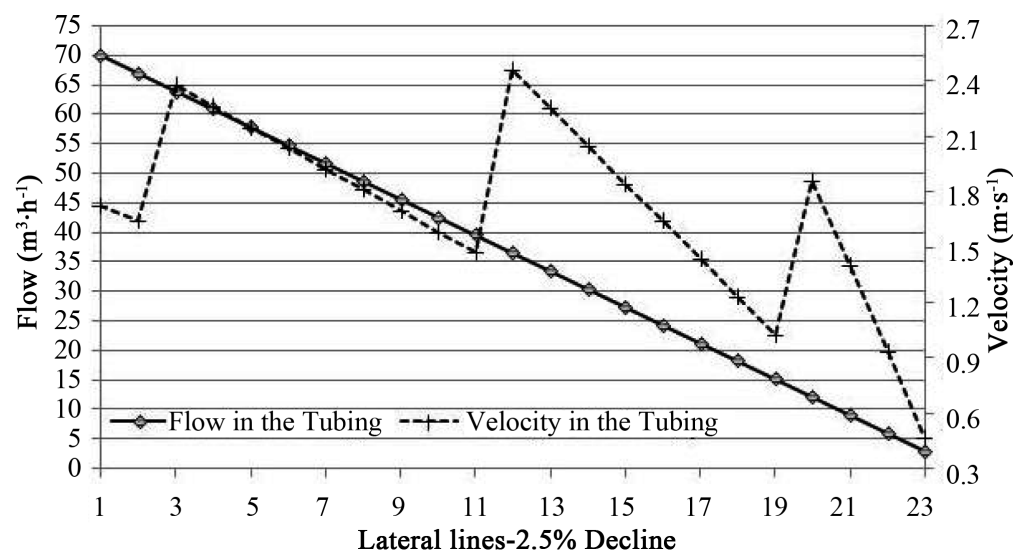

Figure 7. The variation in the calculated velocity in the dimensions of the derivation line, with a distributed flow in the tubing and different diameters in each stretch of the tubing (DLD1 $=120.0 \mathrm{~mm}$, DLD2 $=97.6 \mathrm{~mm}$, DLD3 $=72.5$ $\mathrm{mm}$ and DLD4 $=48.1 \mathrm{~mm}$ ) for a slope of $2.5 \%$.

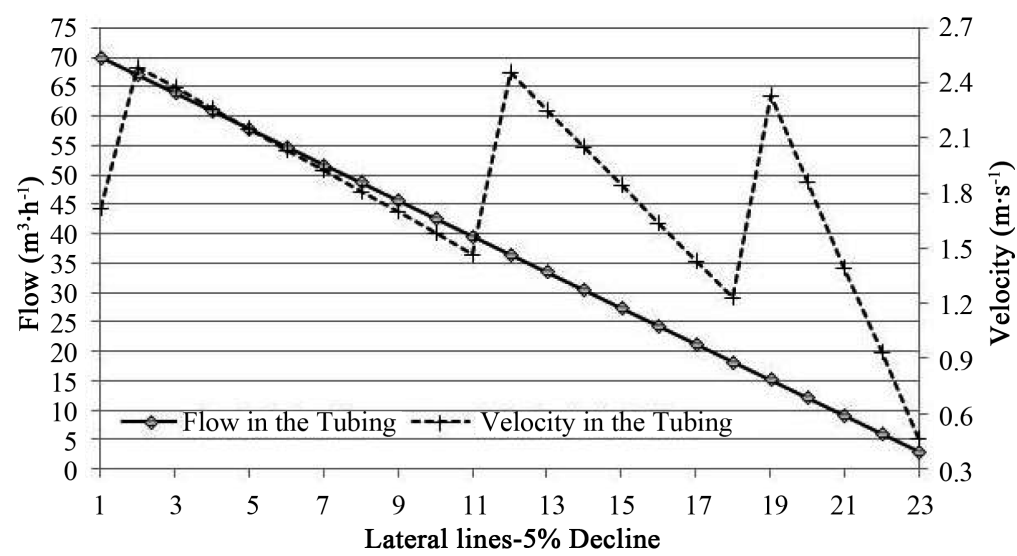

Figure 8. The variation in the calculated velocity in the dimensions of the derivation line, with a distributed flow in the tubing and different diameters in each stretch of tubing $(\mathrm{DLD} 1=120.0 \mathrm{~mm}$, DLD2 $=97.6 \mathrm{~mm}$, DLD3 $=72.5$ $\mathrm{mm}$ and DLD4 $=48.1 \mathrm{~mm}$ ) for a slope of $5 \%$. 


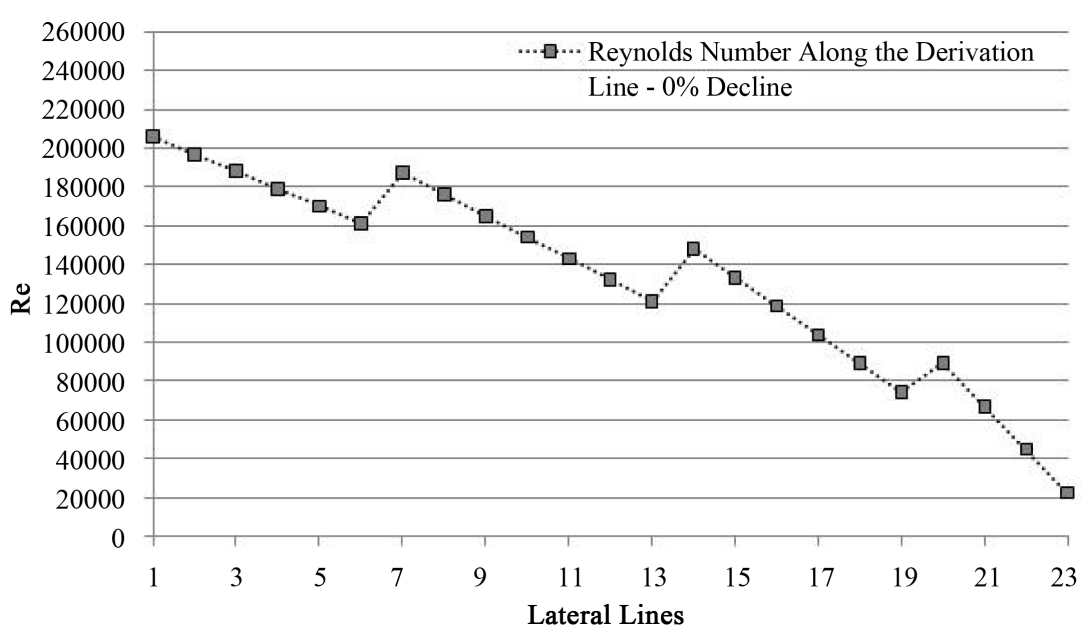

Figure 9. The variation in the Reynolds along the derivation line under a distributed flow with a slope of $0 \%$.

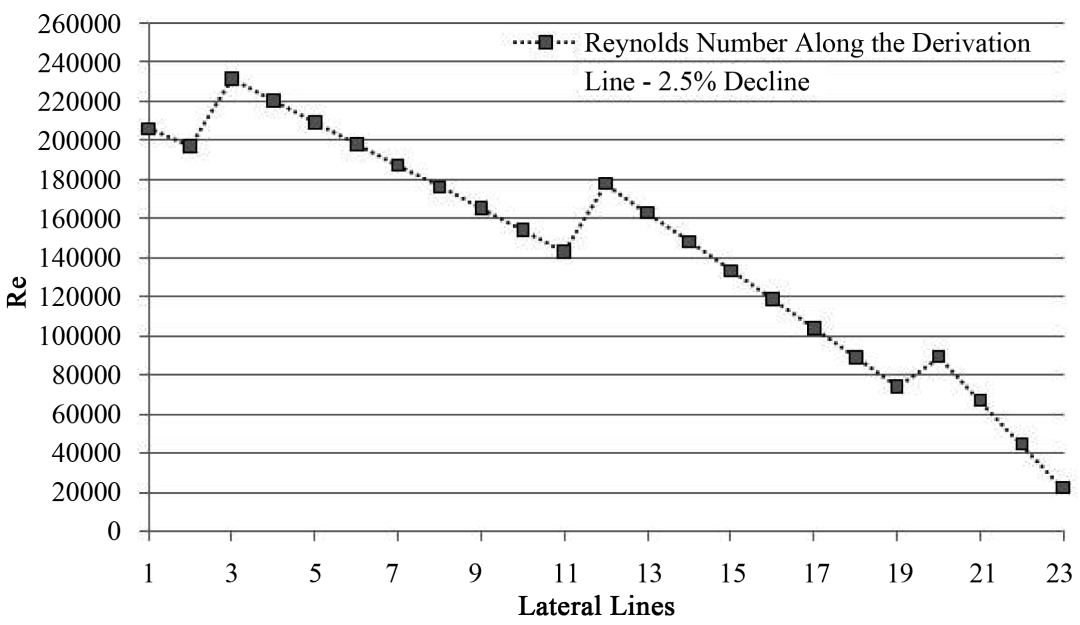

Figure 10. The variation in the Reynolds along the derivation line under a distributed flow with a slope of $2.5 \%$.

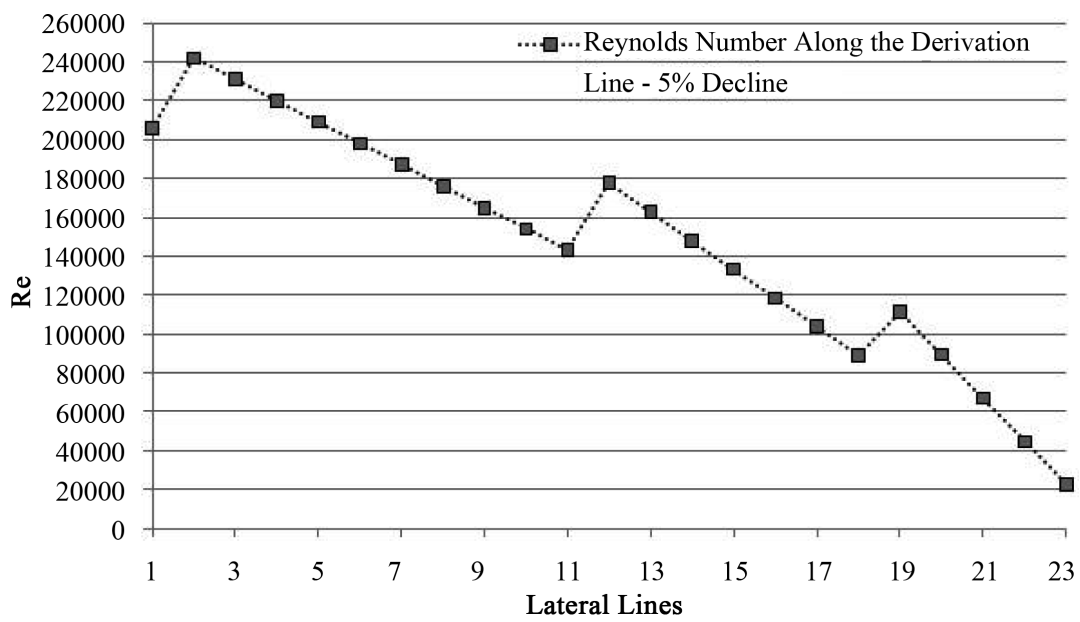

Figure 11. The variation in the Reynolds along the derivation line under a distributed flow with a slope of $5 \%$. 


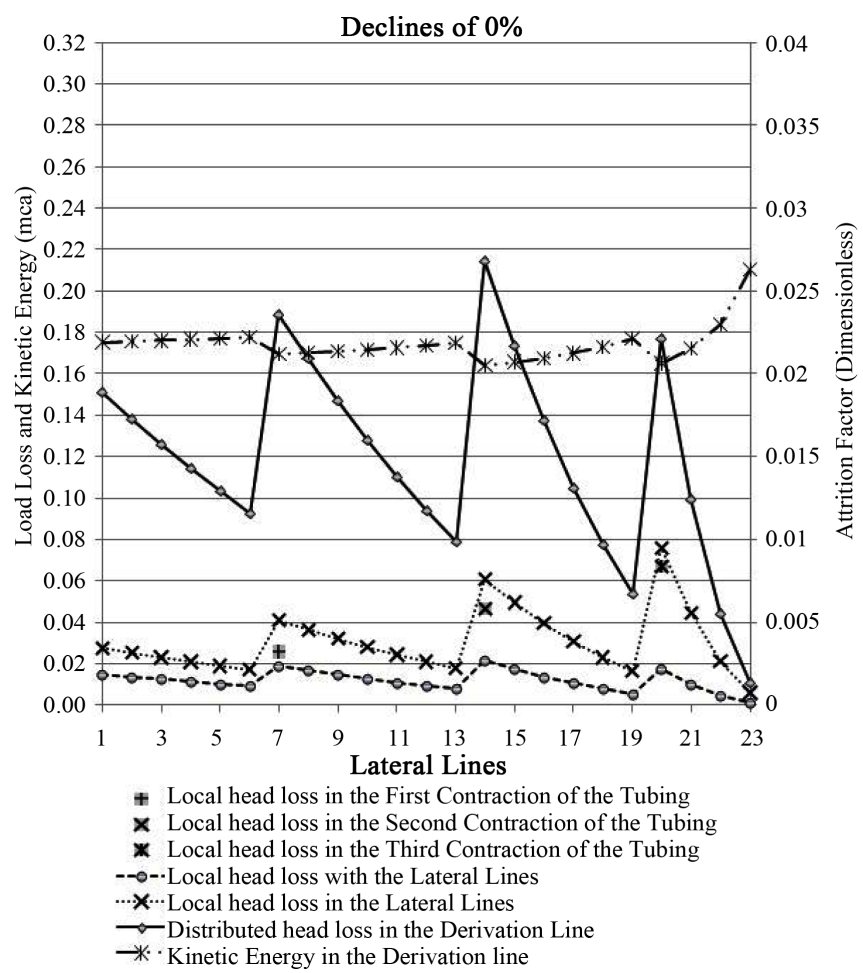

Figure 12. The local head loss in the first, second and third contractions of the tubing and the behaviour of the local head loss in the lateral lines and the head loss unit between the lateral lines and the friction factor and kinetic energy in the derivation line under a distributed flow. Data were obtained from the dimensions of the network with a $0 \%$ slope.

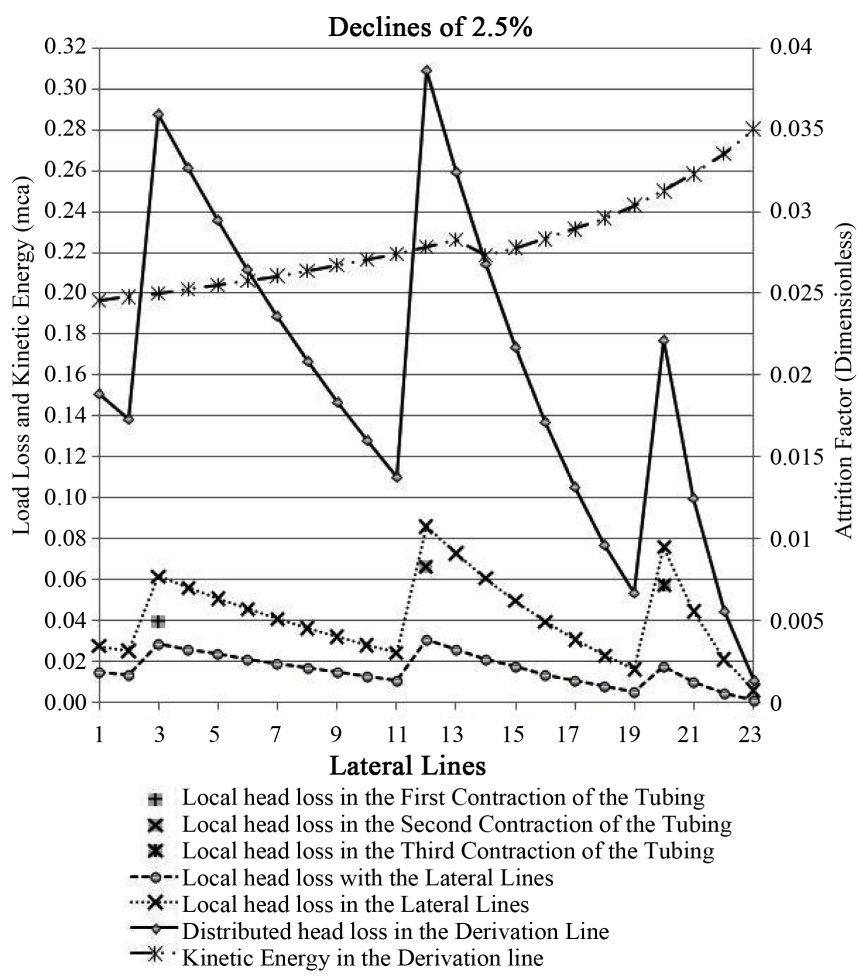

Figure 13. The local head loss in the first, second and third contractions of the tubing and the behaviour of the local head loss in the lateral lines and the head loss unit between the lateral lines and the friction factor and kinetic energy in the derivation line under a distributed flow. Data were obtained from the dimensions of the network with a 2.5\% slope. 


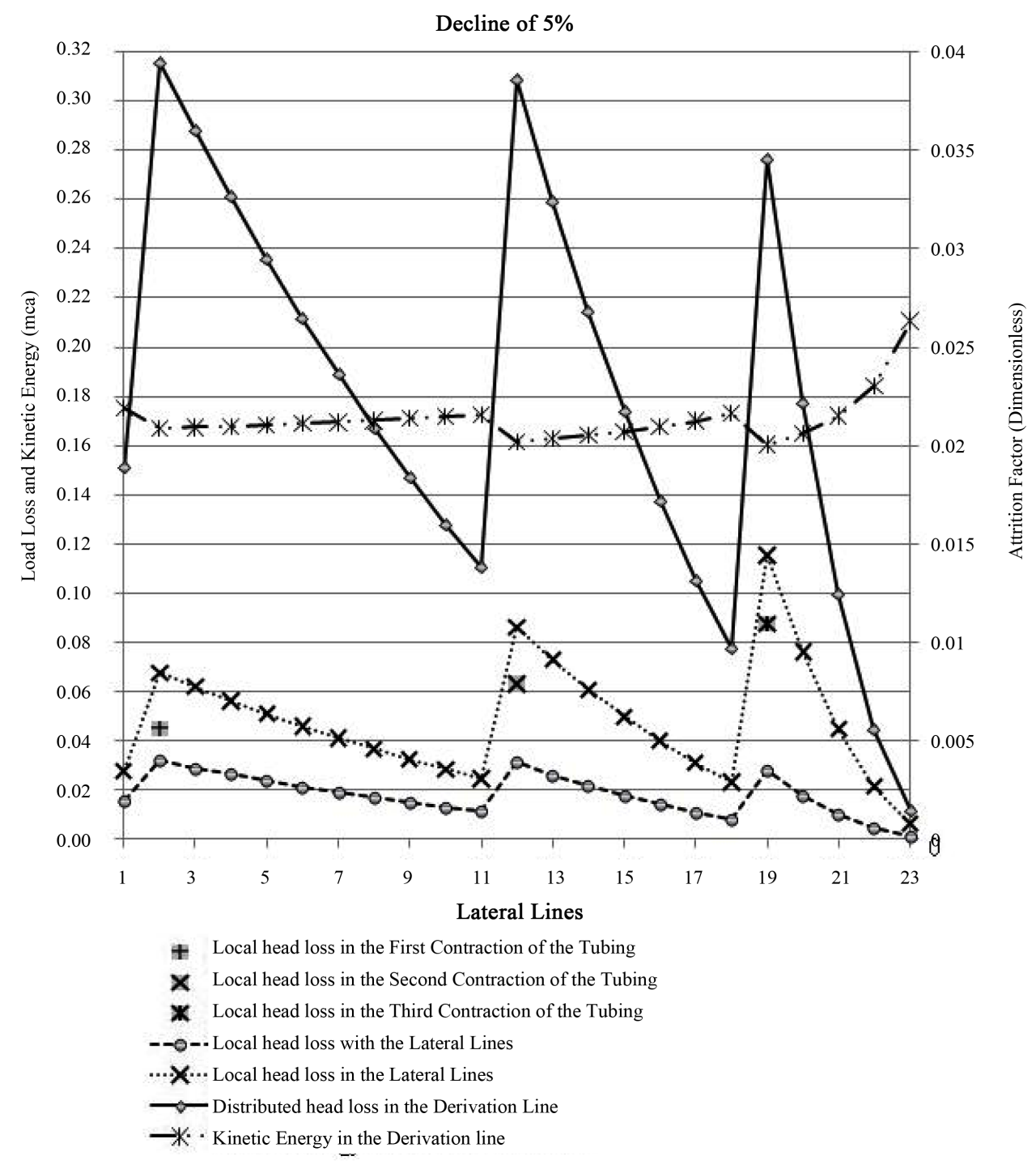

Figure 14. The local head loss in the first, second and third contractions of the tubing and the behaviour of the local head loss in the lateral lines and the head loss unit between the lateral lines and the friction factor and kinetic energy in the derivation line under a distributed flow. Data were obtained from the dimensions of the network with a $5 \%$ slope.

considerable increase in the variation of the values for slopes of $2.5 \%$ and $5 \%$. This shows that as the slope of the terrain increased, all of the parameter values tended to increase, including the amplitude of the local head loss with a contraction in the tubing and the attachment of the lateral lines and the head loss unit between the lateral lines and the friction factor and kinetic energy in the derivation line under a distributed flow.

Figures 15-17 present the energy line, the piezometric line, the pressure head line and the elevation of the derivation line under a distributed flow.

For a slope of $0 \%, 2.5 \%$ or $5 \%$, the kinetic energy (Figures 15-17) in the tubing contributed to the distance between the energy line and the piezometric lines at the beginning of the 4 stretches of the derivation line. At the ends of the four stretches of the tubing, the values of the energy line and of the piezometric line were very close because of the contraction of the tubing, and they were essentially equal at the end of the fourth stretch, when the value of the kinetic energy was close to zero. Additionally, in the comparative analysis of Figures 9-11, the $2.5 \%$ slope favoured a better distribution of the energy line and the piezometric line in the tubing because of the gain in energy, which was offset by the total head loss in the tubing.

Figure 16 and Figure 17 show the influence of the elevation and the respective gain in energy (with the tub- 


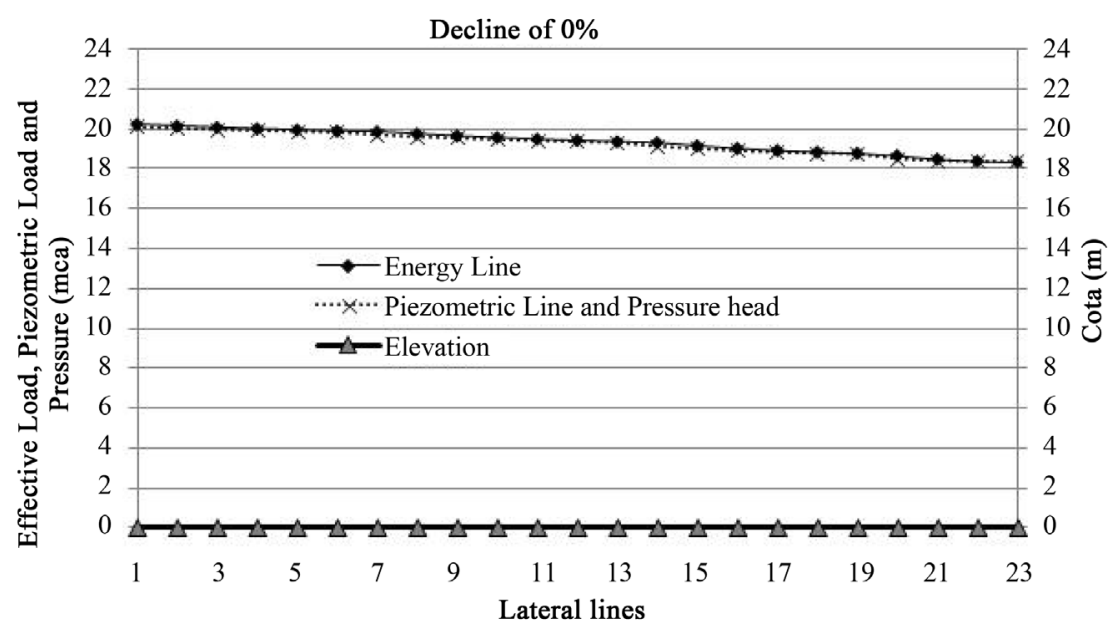

Figure 15. The variation in the energy line, the piezometric line, the pressure head and the elevation of the derivation line under a distributed flow for a $0 \%$ slope.

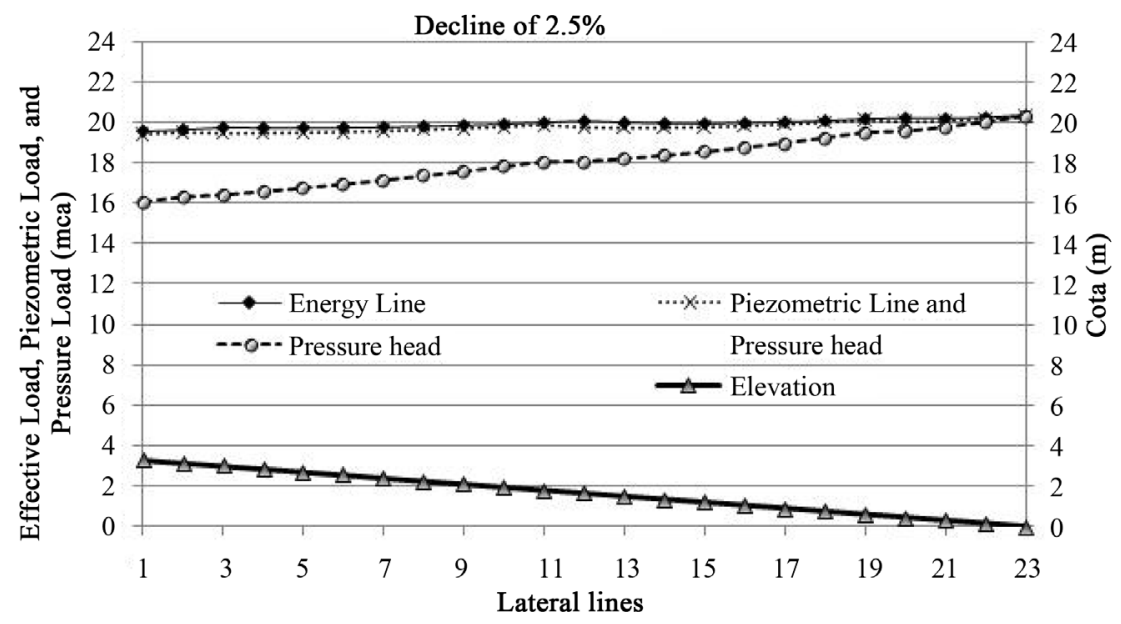

Figure 16. The variation in the energy line, the piezometric line, the pressure head and the elevation of the derivation line under a distributed flow for a $2.5 \%$ slope.

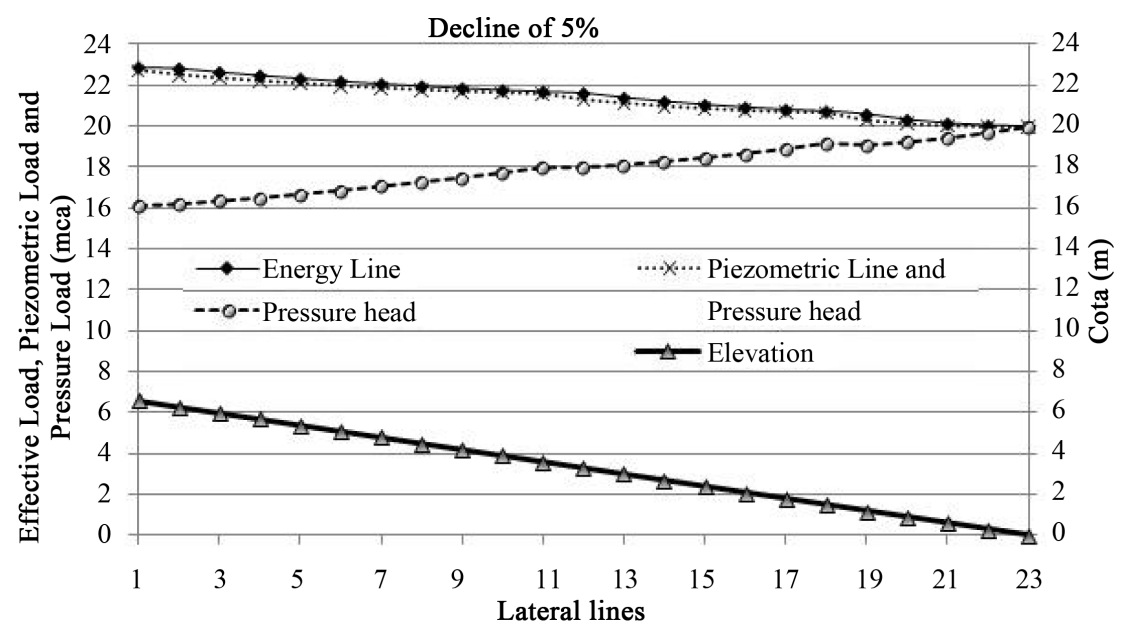

Figure 17. The variation in the energy line, the piezometric line, the pressure head and the elevation of the derivation line under a distributed flow for a $5 \%$ slope. 
ing at a downward slope) on the energy, piezometric and pressure headlines. This influence determined the distributions in the entire operational unit and, consequently, the flow distribution and the production distribution of the entire area. The clearly and detailed indicate the relationship of each part can be find in [20].

\section{Conclusions}

The results of this study suggested that there was a gain in total head at the beginning of the tubing with an increase in the decline of the terrain (for tubing with a distributed flow) and that the gain was gradually lost along the tubing. There was also a decrease in the pressure at the beginning of the tubing, which gradually increased until the end of the tubing.

From these results, it can be concluded that the lowest average velocity $\left(1.49 \mathrm{~m} \cdot \mathrm{s}^{-1}\right)$ was obtained in the tubing with a $0 \%$ slope, followed by the tubing with $2.5 \%\left(1.71 \mathrm{~m} \cdot \mathrm{s}^{-1}\right)$ and $5 \%\left(1.80 \mathrm{~m} \cdot \mathrm{s}^{-1}\right)$ downward slopes. Thus, there tended to be an increase in the average velocity of the tubing of the derivation line when there was an increase in the decline under the same distributed flow.

The results also showed that for tubing with a distributed flow, the influence of the behaviour of the kinetic energy in the tubing increased the distance between the energy line and the piezometric line at the beginning of each stretch after a decrease in the diameter of the tubing. At the end of the tubing, the values of the energy line and the piezometric line were very similar, and they were essentially equal at the final opening.

The hydraulic analysis showed energy and pressure behaviours that are appropriate for water distribution networks with multiple derivations. The analysis criteria, in relation to the differentiation of the components of the energy line and the piezometric line, facilitated a better hydraulic understanding of the network and the verification of the behaviour of the system, while simulating its operation.

The genetic algorithm used in this hydraulic optimisation resulted in a satisfactory resolution of the problem, without making it necessary to introduce simplifications of the dimensions in the formulation of the code for the capability function.

\section{Acknowledgements}

The authors would like to thank CAPES, PROEX and the CNPq-Brazil (processes 141159/2006-5 and 504892/ 2008-8) for the financial support that made this study possible.

\section{References}

[1] Kuwabara, G. and Matsura, E.E. (1996) An Evaluation of the Hydraulic Behaviour of the Lateral Lines of Dripper Tubes. In: National Congress OF Irrigation and Drainage, 11. 1996, Campinas. Anais... Viçosa: Brazilian Association of Irrigation and Drainage, 275-287.

[2] Santiago, F.S., Montenegro, A.A.A. and Montenegro, S.M.G.L. (2004) Evaluation of Hydraulic Parameters and the Management of Microsprinkler Irrigation in a Settlement Area. Engenharia Agrícola, 24, 632-643. http://dx.doi.org/10.1590/S0100-69162004000300015

[3] Souza, I.H., Andrade, E.M. and Silva, E.L. (2005) Design and Hydraulics Evaluation of a Low-Head Microirrigation Bubbler System. Engenharia Agrícola, 25, 264-271. http://dx.doi.org/10.1590/S0100-69162005000100029

[4] Saad, J.C.C. and Mariño, M.A. (2002) Optimum Design of Microirrigation Systems in Sloping Lands. Journal of Irrigation and Drainage Engineering, 128, 116. http://dx.doi.org/10.1061/(ASCE)0733-9437(2002)128:2(116)

[5] Saad, J.C.C. and Frizzone, J.A. (1996) Design and Management Optimization of Trickle Irrigation System Using Non-Linear Programming. Journal of Agricultural Engineering Research, 64, 109-118. http://dx.doi.org/10.1006/jaer.1996.0052

[6] Lucena, K.F.M. and Matos, J.A. (2001) Economic Analysis of Sub-Units of Localised Irrigation. In: Brazilian Congress of Agricultural Engineering, 30, 2001. Foz do Iguaçu: Anais... Foz do Iguaçu: Brazilian Association of Agricultural Engineering, 2001. 1 CD-ROM.

[7] Sarkar, S., Goswami, S.B., Mallick, S. and Nanda, M.K. (2008) Different Indices to Characterize Water Use Pattern of Micro-Sprinkler Irrigated Onion (Allium cepa L.). Agricultural Water Management, 95, 625-632. http://dx.doi.org/10.1016/j.agwat.2008.01.002

[8] Sezen, S.M., et al. (2011) Comparison of Drip and Sprinkler Irrigation Strategies on Sunflower Seed and Oil Yield and Quality under Mediterranean Climatic Conditions. Agricultural Water Management, 98, 1153-1161. http://dx.doi.org/10.1016/j.agwat.2011.02.005 
[9] Gomes, A.W.A., Frizzone, J.A., Rettore Neto, O. and Miranda de, J.H. (2010) Localised Head Loss in Drippers Integrated into Polyethylene Tubes. Scielo Web Publishing. http://www.scielo.br/scielo.php?script=sci_arttext\&pid=S0100-69162010000300008\&lng=pt\&nrm=iso

[10] Zitterell Danieli, B., et al. (2009) Head Loss of Microtubes and Connectors Used in Irrigation. Publishing Scielo Brasil. http://www.scielo.br/scielo.php?script=sci arttext\&pid=S0100-69162010000300008\&lng=pt\&nrm=iso

[11] Jin, X., Zhang, J., Gao, J. and Wu, W. (2007) Multi-Objective Optimization of Water Supply Network Rehabilitation with Non-Dominated Sorting Genetic Algorithm-II. Journal of Zhejiang University SCIENCE A, 9, 391-400. http://www.springerlink.com/content/e21522736v131826/fulltext.pdf

[12] Opan, M. (2010) Irrigation-Energy Management Using a DPSA-Based Optimization Model in the Ceyhan Basin of Turkey. Journal of Hydrology, 385, 353-360. http://dx.doi.org/10.1016/j.jhydrol.2010.03.003

[13] Singh, R.M. (2010) Design of Barrages with Genetic Algorithm Based Embedded Simulation Optimization Approach. Water Resources Management, 25, 409-429. http://www.springerlink.com/content/d276u4327rr80n80/fulltext.pdf

[14] Scaloppi, E.J. (1988) Adjusted F Factor for Multiple-Outlet Pipes. Journal of Irrigation and Drainage Engineering, 114, 169-174. http://dx.doi.org/10.1061/(ASCE)0733-9437(1988)114:1(169)

[15] Swamee, P.K. (1993) Design of a Submarine Pipeline. Journal of Transportation Engineering, 119, 159-170. http://dx.doi.org/10.1061/(ASCE)0733-947X(1993)119:1(159)n

[16] Porto, R.M. (2006) Basic Hydraulics. 4th Edition, Rettec Gráfica and Editor, São Paulo.

[17] Aneel, National Agency of Electric Energy (2006) Homologation Resolution No. 313 on the Fees for Providing Electric Energy. ANNEL Web Publishing, Brasilia, 12 p. http://www.aneel.gov.br/cedoc/reh2006313.pdf

[18] Noronha, J.F. and Latapia, M.X.I.C. (1998) Custos de produção sob condições de risco no estado de São Paulo. Revista de Economia e Sociologia Rural, 26, 275-287.

[19] Frizzone, J.A. (2005) Análise de decisão econômica em irrigação. ESALQ, Piracicaba, 371 p.

[20] Marcuzzo, F.F.N. (2008) Sistema de otimização hidráulica e econômica de rede de irrigação localizada usando algoritmos genéticos. Tese de doutorado. EESC/USP, São Carlos, 361 p. http://www.teses.usp.br/teses/disponiveis/18/18138/tde-11112008-091041/pt-br.php

[21] Marcuzzo, F.F.N. and Wendland, E. (2010) Efeito da variação na tarifação pelo uso da água no dimensionamento otimizado de rede de irrigação localizada usando algoritmos genéticos. Revista Brasileira de Recursos Hídricos, 15, 109118.

https://www.abrh.org.br/sgcv3/UserFiles/Sumarios/0965dabc71f46b05537f68871d5ed280 de994387275c4b2e632735 0b0de23f65.pdf

[22] Marcuzzo, F.F.N. and Wendland, E. (2010) Otimização de rede de irrigação de microaspersão usando algoritmos genéticos sob diferentes declividades e tarifação de água e energia elétrica. Engenharia na Agricultura, 18, 50-62. http://www.seer.ufv.br/seer/index.php/reveng/issue/view/12/showToc

[23] Marcuzzo, F.F.N. and Wendland, E. (2011) Distribuição de pressão em rede de irrigação localizada otimizada por algoritmos genéticos. Engenharia Agrícola, 31, 497-505. http://dx.doi.org/10.1590/S0100-69162011000300010 
Scientific Research Publishing (SCIRP) is one of the largest Open Access journal publishers. It is currently publishing more than 200 open access, online, peer-reviewed journals covering a wide range of academic disciplines. SCIRP serves the worldwide academic communities and contributes to the progress and application of science with its publication.

Other selected journals from SCIRP are listed as below. Submit your manuscript to us via either submit@scirp.org or Online Submission Portal.
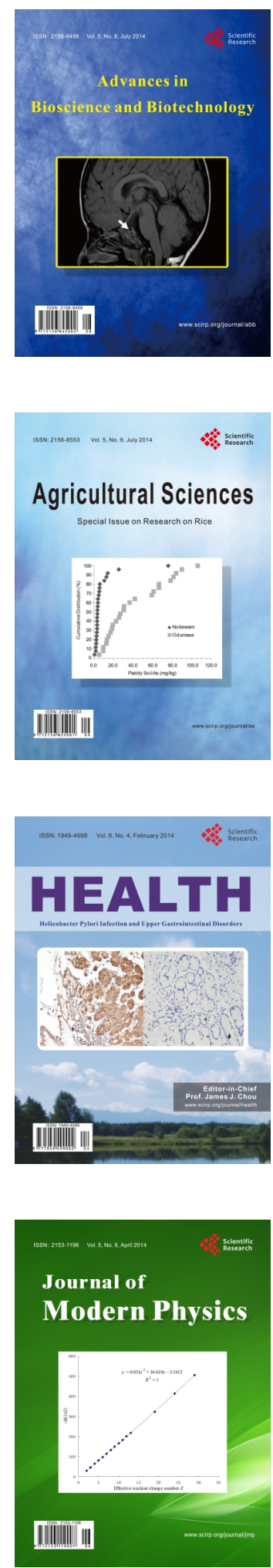
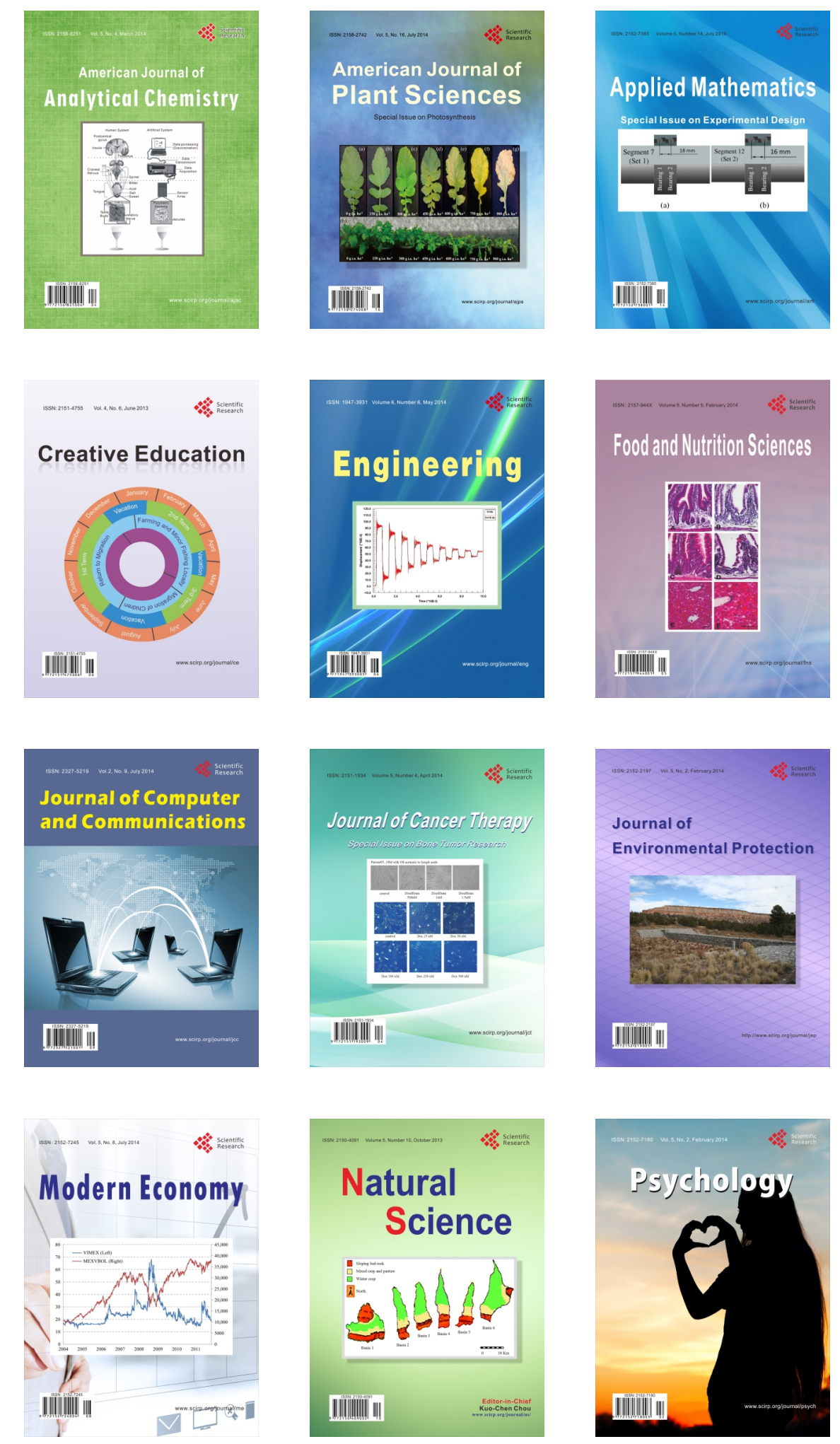